\title{
Analysis of Tensile Strenght and Shear Modulus of GRE Pipe using Ansys
}

\author{
Dita Puspita ${ }^{1, a}$, Siti Lailatul Arofah ${ }^{1}$, Elok Hidayah ${ }^{1}$, Lutfi Rohman ${ }^{1}$ and \\ Ratna Dewi Syarifah ${ }^{1}$
}

${ }^{1}$ Department of Physics, Faculty of Mathematics and Natural Sciencs, University of Jember, Jalan Kalimantan No 37 Jember 68121, Indonesia

aummusafiyah88@gmail.com

\begin{abstract}
Composite materials (GRE pipe) had been applied in various industries. These kind application are based on the advantages of composite properties, that are lightweight, high corrosion resistance and low cost. In order to make a lightweight and strong materials, some materials that light and stiff had been widely used, lie fiber glass, epoxy and the other. These materials (fiber glass and epoxy) are synthetic and non-biodegradable, but give some advantages in composite to make composite more stiff, light and strong. Mechanical properties of fiber glass composites had been doing based on theory through modeling. Theoretical results obtained showed that maximum stress and shear modulus value of GRE pipe are less than each components (glass fiber and epoxy resin). Each value of maximum stress and shear modulus are $584.57 \mathrm{MPa}$ and $46.15 \mathrm{MPa}$.
\end{abstract}

Keywords: composite material, Ansys, GRE pipe

\section{Introduction}

Composite material is a material consisting of two or more constituent materials which physically and mechanically can be distinguished from one another [1]. Composite material consists of two main components, namely reinforcement and matrix. Reinforcement is a component that determines the strength and stiffness of the composite material. While the matrix is a material that functions to bind and protect the composite material from external influences [2]. Composite materials have been widely applied in various industrial fields [3,1] because of their relatively cheap production costs, strength, light weight, and resistance to corrosion [4]. One of the applications of composite materials is the oil and gas industry pipes.

Metal pipe is a pipe that is often used in the oil and gas industry because of its excellent strength. However, metal pipes also have disadvantages, namely low corrosion resistance. Especially for the offshore oil and gas industry, corrosion problems in pipes often occur both inside and outside the pipe. Corrosion of the inner pipe usually occurs due to the reaction between the pipe building materials and gases such as carbon dioxide (CO2) and hydrogen sulfide $\left(\mathrm{H}_{2} \mathrm{~S}\right)$ [5]. Due to corrosion in pipes causing several operational and health problems which are commonly referred to as the cases of CAPEX and OPEX (capital and operational expenditures) and HSE (health, safety, and the environment) in the oil and gas industry. Most of the reported corrosion was due to carbon dioxide gas and caused a $25 \%$ safety incident problem, $2.2 \%$ real assets, an $8.5 \%$ increase in capital expenditure, a $5 \%$ loss / deferred production, and an $11.5 \%$ increase in pipeline lifting costs [6]. Therefore a pipe with strong mechanical properties and corrosion resistance is needed. 
One type of pipe that suits these conditions is a pipe made of GRE (glass reinforced epoxy) composite material, which is a composite material with a matrix in the form of epoxy and a glass fiber reinforcement [7]. Epoxy is used as a matrix because it has the best chemical resistance among other resins (isophatalic polyester, vinyl ester, and phenolics) [8]. GRE pipes are designed to withstand high pressure, light weight, and have high strength so that they can be properly applied to the oil and gas industry.

The use of GRE composite materials for the manufacture of oil and gas industry pipes needs to pay attention to its mechanical properties. Mechanical properties are parameters used to determine the strength and suitability of a material before it is applied as a product. The test used is the tensile test. Through the tensile test it can be seen the tensile strength and modulus of elasticity of the material [9]. Tensile strength is the maximum tensile stress a material can accept without causing local fracture [10]. While the modulus of elasticity is a mechanical property that shows the stiffness of a material. The greater the modulus of elasticity, with the application of the same force, the material will experience a slight change compared to materials with a small modulus of elasticity [11].

GRE pipe testing is done using Ansys software. Ansys is a program used to model finite elements to solve cases related to mechanics, including static, dynamic, fluid structural analysis, as well as cases related to acoustics and electromagnetics. Testing is done by making the pipe geometry and then inputting the GRE material parameters. Testing by means of modeling is carried out to obtain an estimate of the material and its mechanical properties before the experiment is carried out, so that the results of the modeling can be used as a consideration when conducting experiments.

\section{Method}

The first step is making a model by inputting data in the form of pipe geometry and GRE material parameters in ANSYS 18.2 software, input parameters such as modulus of elasticity. Poisson ration, thickness, radius, length, and density are inputted. Then do the meshing process. Because the method used in Ansys is the finite element method, when meshing the geometric surface it will be divided into small squares (1835 nodes and 1518 elements). The next step is to input the boundary conditions on the pipe geometry that has been made. Then tested and then analyzed the results.

\section{Results and Discussion}

Composite material synthesis is one of the methods used to improve the mechanical properties of each component of the composite material. analysis of the mechanical properties of composite materials can be done directly through experiments, and indirectly by modeling. Modeling is one way that can be done to estimate the shape and mechanical properties of the materials to be made, so that the determination of materials for certain applications becomes easier. In this research, glass fiber and epoxy resin are combined to manufacture GRE (Glass Reinforce Epoxy) pipes. The geometry obtained based on the modeling results is shown in Figure 1. 

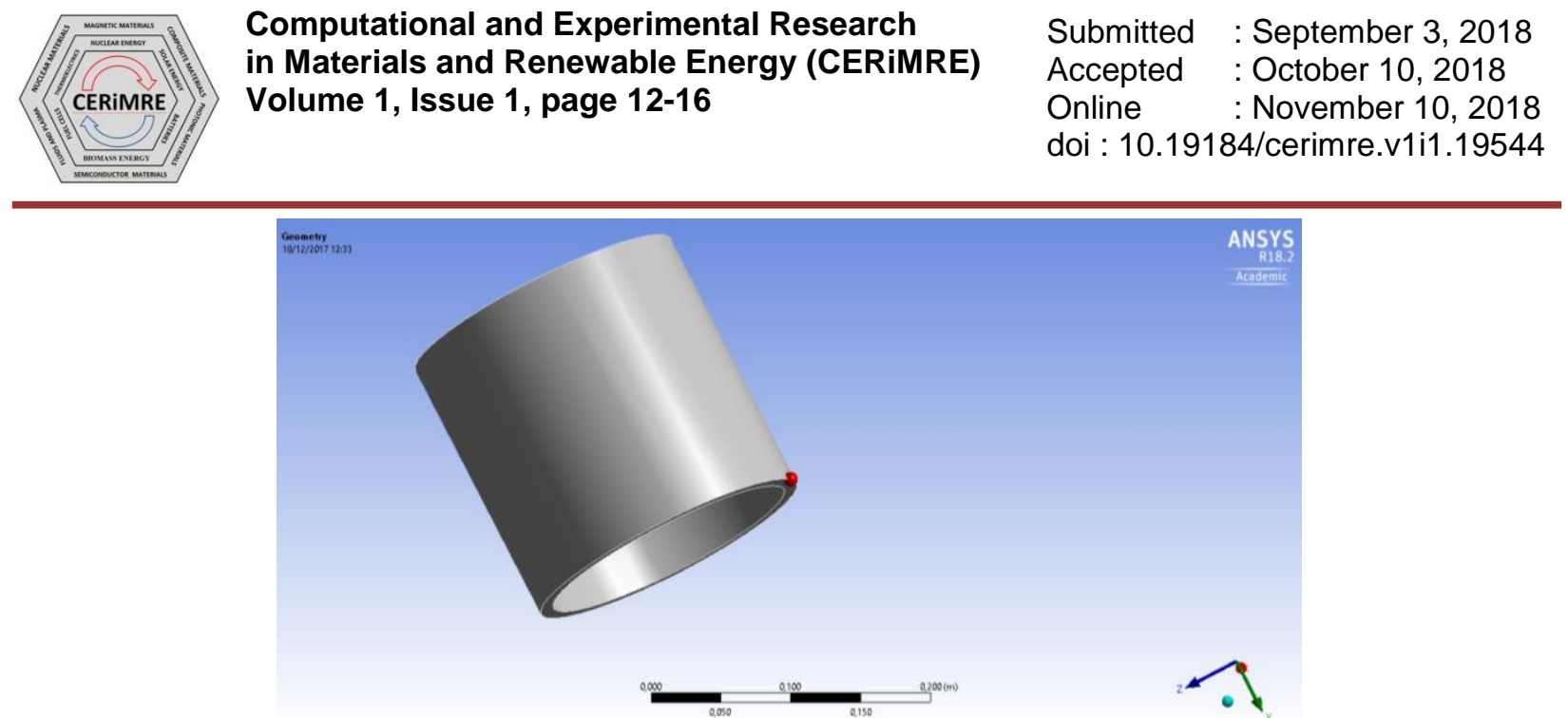

Figure 1. The geometry of the GRE pipe the resulting GRE pipe has an inner diameter of $20 \mathrm{~cm}$, an outer diameter of $22 \mathrm{~cm}$, a height of $30 \mathrm{~cm}$ and a thickness of $2 \mathrm{~cm}$.

The tensile test is carried out by determining the points on the pipe as the location to be drawn, the direction of pull and the static point of the pipe. The static point is the part of the pipe that is fixed or not moving, because in this simulation the pulling force is only applied to one end of the material, while the other end is fixed. There are several mechanical properties produced by modeling this GRE pipe, including maximum tensile stress, maximum strain, maximum deformation and shear modulus.

Modeled GRE pipe has a maximum tensile stress of $584.57 \mathrm{MPa}$, as shown in Figure 2. This value is still smaller than the maximum tensile stress possessed by glass fiber and epoxy resin. Some things that may affect the maximum tensile stress value are the meshing size that is too large, so it does not represent all elements in the pipe. Another factor is the geometry of the material in the form of a hollow pipe. The presence of a cavity may contribute to the reduced mechanical properties of the synthesized composite material. The shear modulus produced by GRE pipe is $46.15 \mathrm{MPa}$. In addition to the tensile stress value, the maximum strain and maximum deformation values of GRE pipe are obtained as shown in Figure 3 and Figure 4. The maximum strain and maximum deformation values of GRE pipe are respectively $7.45 \%$ and $0.1058 \mathrm{~cm}$.

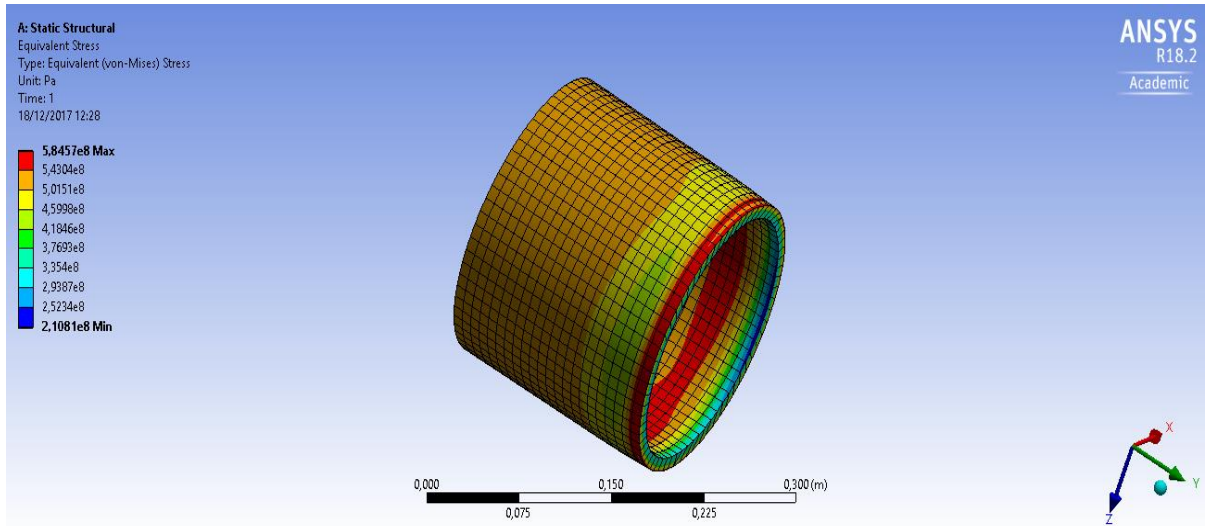

Figure 2. The maximum tensile stress of the GRE pipe 

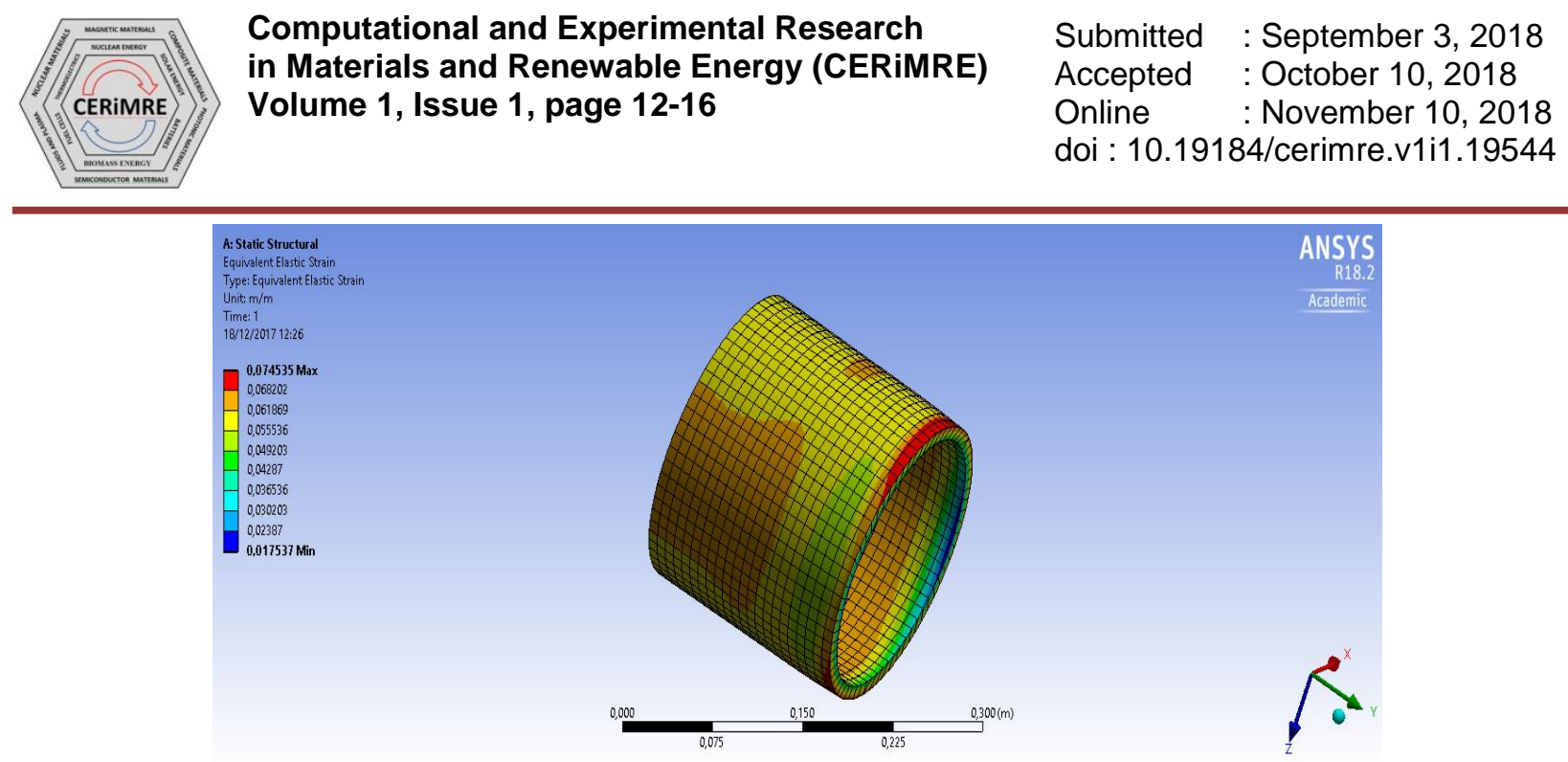

Figure 3. The maximum strain of the GRE pipe

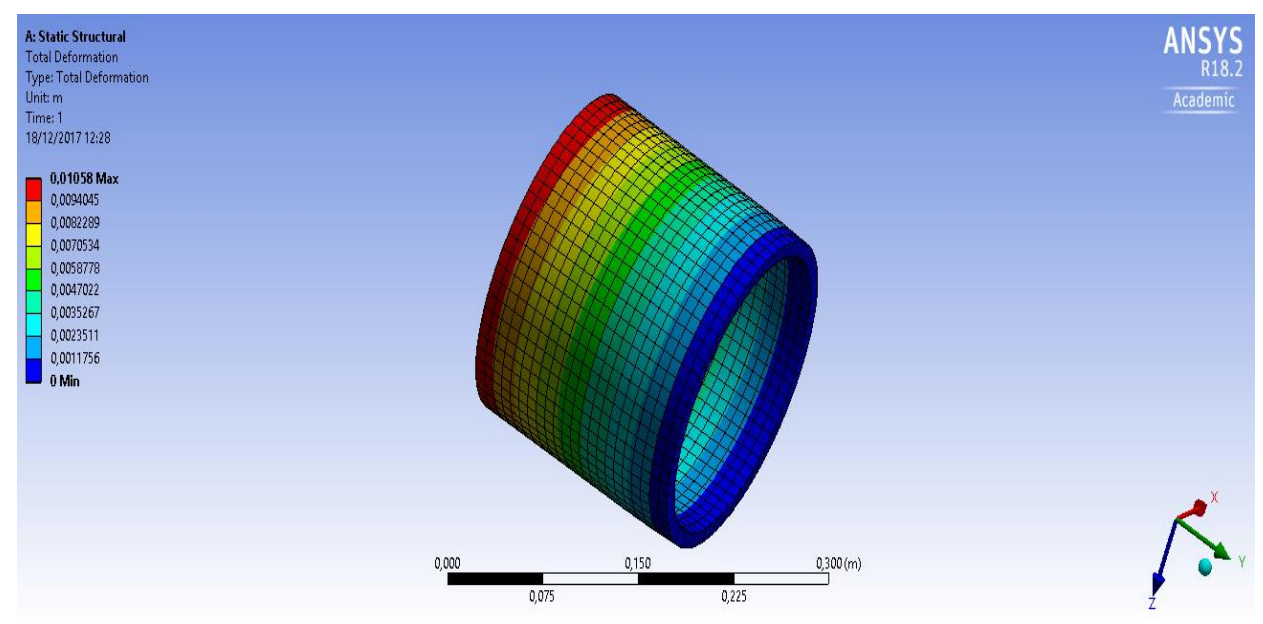

Figure 4. Maximum deformation of GRE pipe

\section{Summary}

Research on the analysis of the tensile strength and shear modulus of GRE pipes has been carried out. The tensile stress value resulting from the modeling is still far different from the maximum tensile stress of epoxy resin and glass fiber. Due to the small tensile stress, the shear modulus is also small. This is presumably due to the large size of the meshing. Therefore, further research can be carried out with a smaller meshing size in order to obtain results with better accuracy.

\section{References}

[1] N Sridhar, D S Dunn, A M Anderko, M M Lencka and H U Schutt, 2000, Effect of Water and Gas Compositions on The Internal Corrosion of Gas Pipelines Modeling and Experimental Studies, Corrosion, volume 57(3).

[2] J M Berthelot, 1999, Composite Materials: Mechanical Behavior and Structural Analysis, New York, Springer. 
[3] P A Fowler, J M Hughes and R M Elias, 2006, Biocomposites: Technology, Environmental Credentials and Market Forces, Journal of the Sciences of Food and Agricultures, volume 86, page $1781-1789$.

[4] M Akay, 2015, An Introduction to Polymer-matrix Composites, http://www.bookbon.com, accessed January 11, 2018.

[5] P Wambua, J Ivens and I Verpoest, 2003, Natural Fiber: Can They Replace Glass in Fiber Reinforced Plastics, Composites Science and Technology, volume 63, page $1259-1264$.

[6] M B Kermani and A Morshed, 2003, Carbon Dioxide Corrosion in Oil and Gas Production-A Compendium, Corrosion, volume 59(8).

[7] S R Frost and A Cervenka, 1994, Glass Fibre-reinforced epoxy matrix filament-wound pipes for use in the oil industry, Composit manufacturing, volume 5(2).

[8] N Himawan, I Rochani and H Ikhwani, Comparative Analysis of Onshore Pipeline Design Using Material Glass Reinforced Polymer (GRP) and Carbon Steel Based on Techno Echonomic.

[9] J R Davis, 2004, Tensile Testing Second Edition, USA: ASM International.

[10] M Ohring, 1995, Engineering Materials Science, California: Academic Press INC.

[11] D Roylance, 2008, Mechanical Properties of Materials, USA: MIT. 